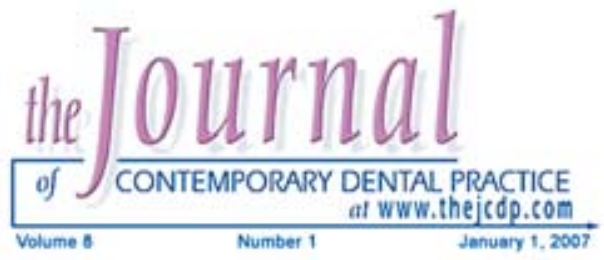

\title{
Tongue Piercing: Case Report of a Local Complication
}

\section{Elio Hitoshi Shinohara, DDS, PhD; Fernando Kendi Horikawa, DDS;} Marcelo Martinson Ruiz, DDS; Mauro Tadachi Shinohara, MD

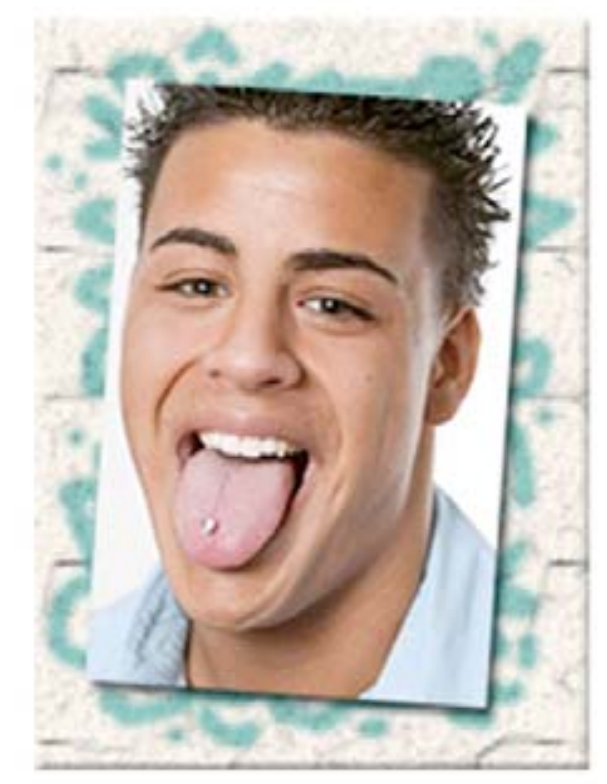

\section{Abstract}

Historically, wearing adornments on pierced body parts has been associated with many cultures as manifestations of religious or cultural identities. Currently, its use has a broad acceptance among young people. The most common sites for piercings are the tongue and lower lip in the oral cavity. Several complications may be associated with this practice with the most frequently observed being halitosis, periodontitis, tooth fracture, glossitis, and the formation of abscesses. This paper is a case report of a patient who had a complication from a piercing on the tongue located under the overlying mucosa. It also suggests a local habit was a possible initiator of this complication.

Keywords: Piercing, tongue, complications, oral surgery

Citation: Shinohara EH, Horikawa FK, Ruiz MM, Shinohara MT. Tongue Piercing: Case Report of a Local Complication. J Contemp Dent Pract 2007 January;(8)1:083-089.

(C) Seer Publishing 


\section{Introduction}

The practice of body ornamentation in the form of piercing and tattoos was adopted by ancient civilizations and remains popular in the western world apparently for the manifestation of selfexpression. ${ }^{1,2}$ Body piercing has become very popular because of its versatility and reversibility.

Oral piercing and its associated hardware may be placed in the lips, tongue, cheeks, or uvula in various combinations. ${ }^{3}$ The lower lips and the tongue are the most common oral sites. ${ }^{8}$ In the tongue wound healing requires approximately four to six weeks to occur due to the constant movement of the tongue. ${ }^{4}$

During the healing period it is recommended alcoholic drinks be avoided as well as smoking and mechanical contact with the lips. When an oral piercing is performed and associated hardware placed, all immediate and subsequent consequences must be considered along with such issues as infection control during the procedure, sterility of the materials, and anatomical conditions. ${ }^{5}$

This paper reports the case of a patient with a tongue piercing which became covered by the ventral mucosa of the tongue. The treatment procedure will be described along with a discussion of the possible cause of the condition.

\section{Case Report}

A 16-year-old white male patient was referred to the Emergency Service at Conjunto Hospitalar do Mandaqui SUS/SP in Sao Paulo, Brazil with the ventral mucosa healed over piercing hardware in the tongue. He reported having undergone tongue piercing four months earlier. One week after the placement he noticed the sphere had penetrated the ventral surface of his tongue. It had been originally placed with a connector ball on the ventral surface. It was under the surface of the ventral mucosa of the tongue when he presented for treatment (Figure 1).

The patient reported he used to move the piercing by biting the metallic pole with the incisors and then pressing the ventrally located stud against the tongue. Clinical examination revealed a globular structure approximately 5 $\mathrm{mm}$ in diameter with hard consistency totally embedded in the ventral surface of the tongue.
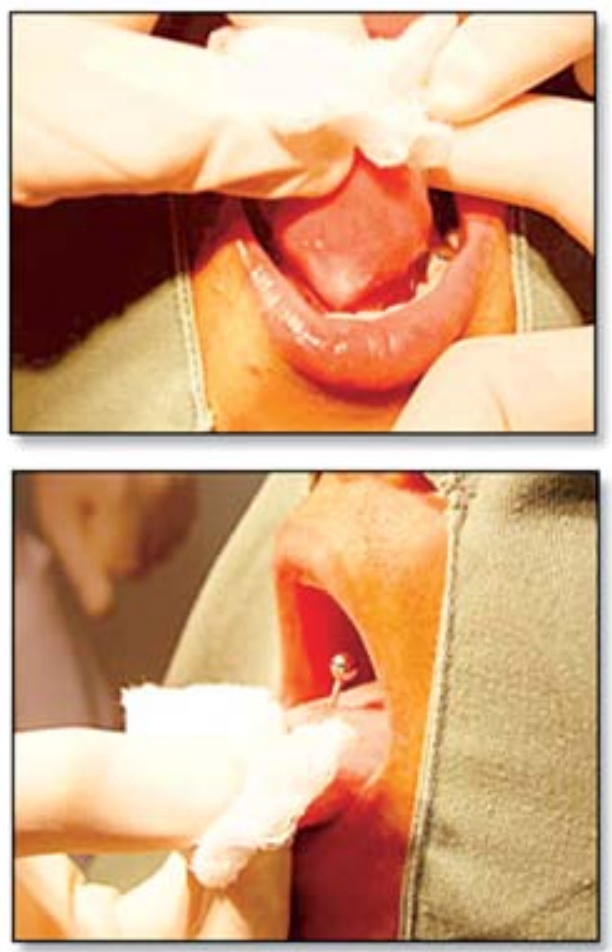

Figure 1. A. Healed piercing site with the hardware stud buried under the ventral mucosa of the tongue. B. Lateral view of tongue piercing. The dorsal stud is positioned properly, but the ventral end is not.
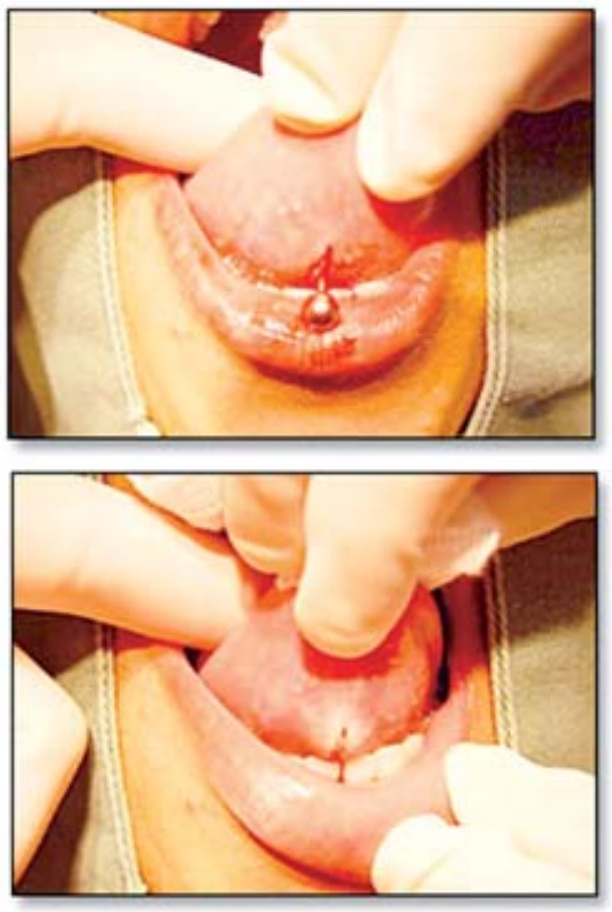

Figures 2 and 3. Exposition of ventral stud after linear incision in midline of the tongue. 
The piercing hardware was exposed using a median incision under local anesthesia (Figures 2 and 3 ). Following tissue separation, the globe was located and removed and a suture was placed. An anti-inflammatory medication was prescribed (Ketoprofen $100 \mathrm{mg} \mathrm{8/8} \mathrm{h)} \mathrm{for}$ three days. Within one week a post-operative examination revealed normal tissue healing without complications.

\section{Discussion}

Oral piercings may cause several complications such as sialorrhea, tooth abrasion, impairment of speech and eating, tooth fracture, oral infections, septicemia, gingival recession, and the risk of aspiration of loose piercing hardware. ${ }^{6}$

Theodossy ${ }^{7}$ first described healing of the ventral mucosa over piercing hardware. He claimed the penetration of the metallic globe was a secondary event following tongue swelling promoted by the perforation of the tongue. Scott et al. ${ }^{8}$ described an odd case where the ventral stud was located in the tongue body. Neither paper in which the ventral stud was located in the tongue describes the possible mechanisms that can cause the tongue hardware to become embedded in this location.

In this case report, the patient reported he was biting the piercing hardware with the incisors then

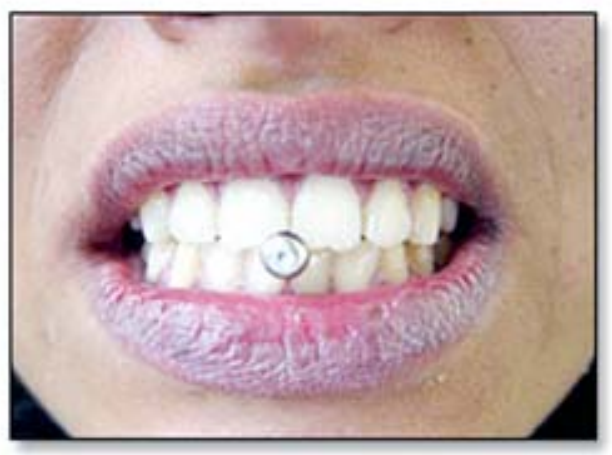

Figure 4. Another patient with a dorsal piercing stud in occlusion. In this case this maneuver probably compressed the ventral stud against the body of the tongue.

pulling the sphere against the tongue. This had probably caused the penetration of the ventral stud into the tongue (Figure 4).

\section{Summary}

To our knowledge, this is the first report of an oral piercing with a portion of the piercing hardware embedded beneath the ventral mucosa in which a possible etiology is offered. The patient's habit of biting and pulling the dorsal ball of the piercing hardware is the likely cause of the penetration of the ventral stud beneath the ventral surface of the tongue prior to healing. The clinical approach to the problem consisted of surgical removal of the ornament. The patient declined to keep the tongue piercing.

\section{References}

1. Scully C, Chen M. Tongue piercing (oral body art). Br J Oral Maxillofac Surg. 1994; 32: 37-38.

2. Peticolas T, Tilliss TS, Cross-Poline GN. Oral and perioral piercing: a unique form of self-expression. J Cont Dent Pract. 2000; 1: 30-46.

3. Shacham R, Zaguri A, Librus HZ, et al. Tongue piercing and its adverse effects. Oral Surg Oral Med Oral Pathol Oral Radiol Endod. 2003; 95: 274-76.

4. Boardman R, Smith RA. Dental implications of oral piercing. Oral Health. 1997; 87: 23-31.

5. McGeary SP, Studen-Pavlovich D, Ranalli DN. Oral piercing in Athletes: implications for general dentists. Gen Dent. 2002 ; 50: 168-72.

6. De Morr RJG, De Witte AMJC, De Bruyne MAA. Tongue piercing and associated oral and dental complications. Endod Dent Traumatol. 2000; 16: 232-37.

7. Theodossy $\mathrm{T}$. A complication of tongue piercing. A case report and review of the literature. $\mathrm{Br}$ Dent J. 2003; 194: 551-552.

8. Scott P, Baker A, Spencer RJ. Oral Piercing and Associated Complications: Two Case Reports. Dent Update 2004; 31:421-22. 
About the Authors

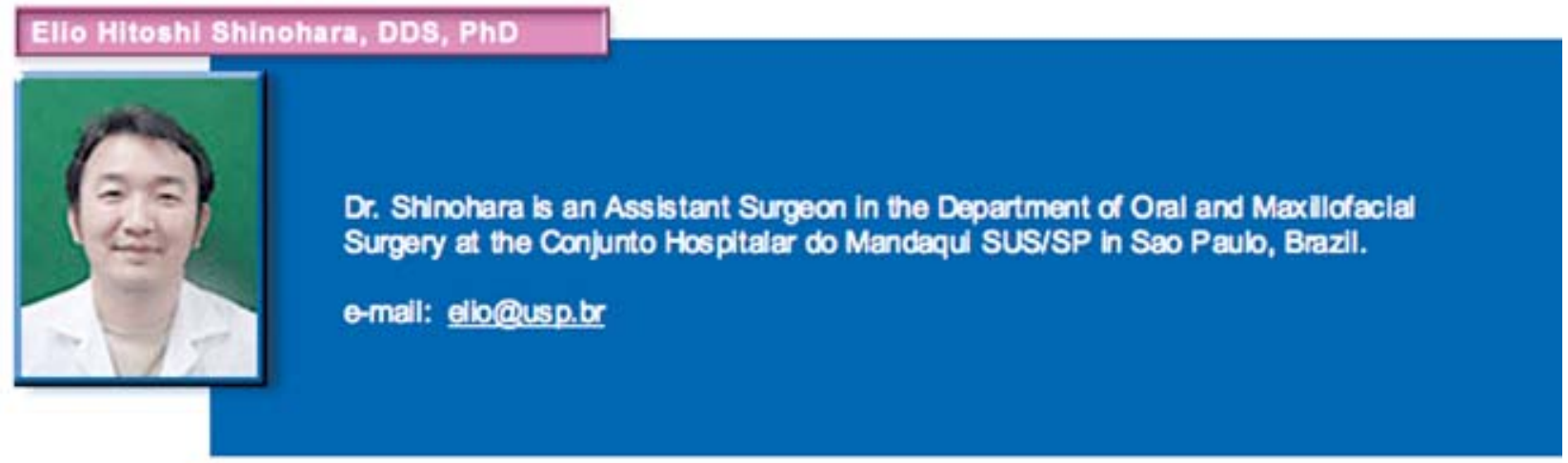

\section{Fornando Kondl Horikawa, DDS}

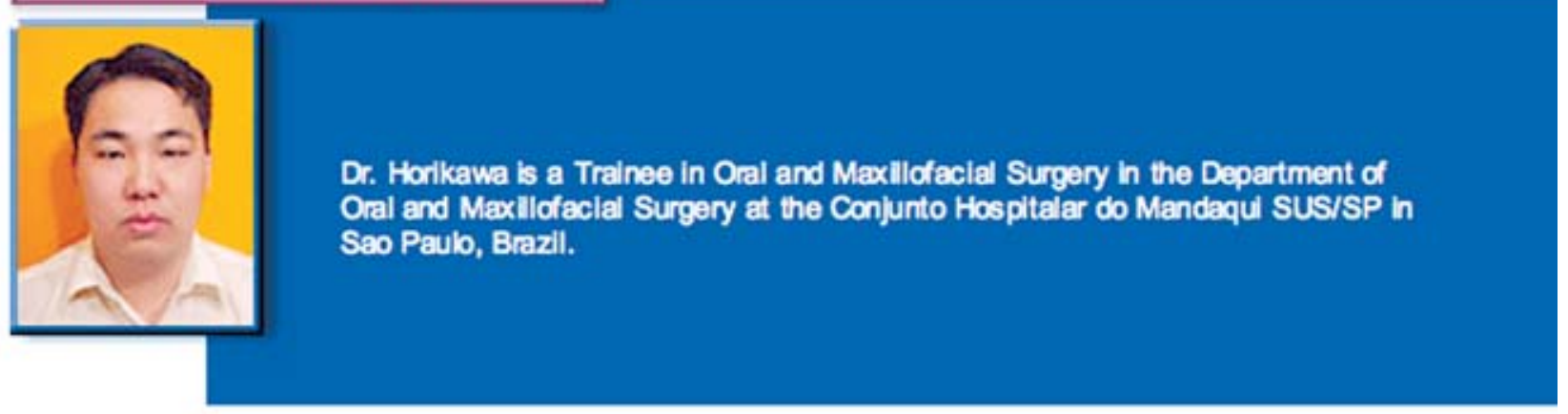

\section{Marcolo Martinson Ruiz, DDS}

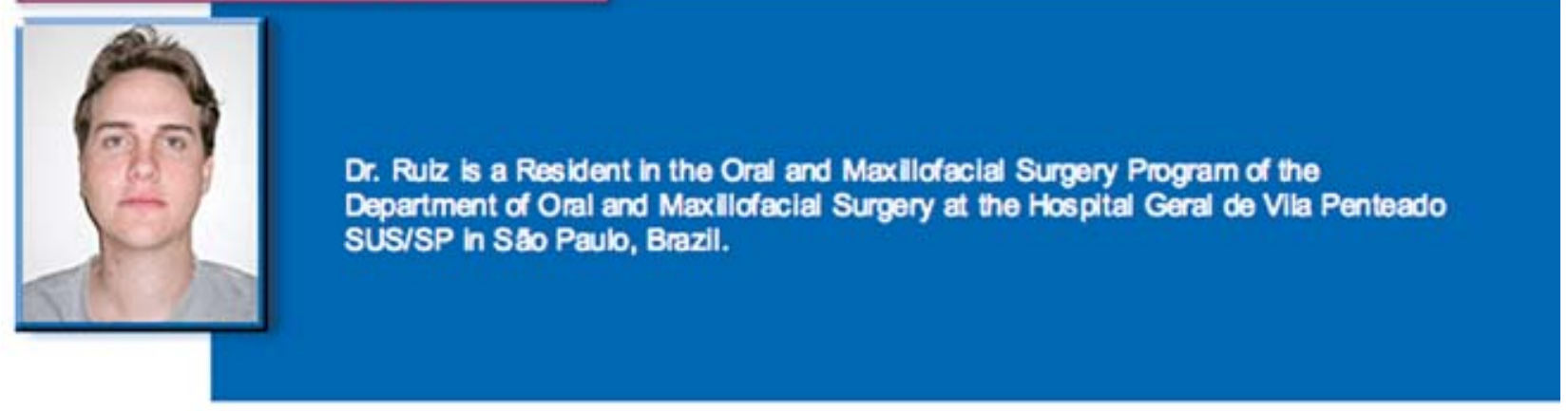

\section{Mauro Tadachl Shlnohara, MD}

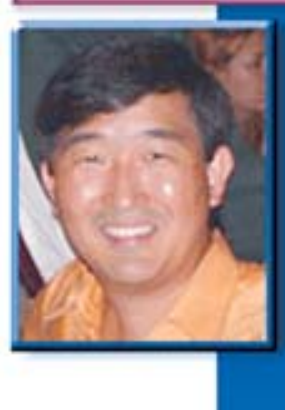

Dr. Shinohara is an Assistant Surgaon in private practice in the Hospital Santa Casa de Misericordla de Limelra in Sab Paulo, Brazll. 